“(C) 2019 IEEE. Personal use of this material is permitted. Permission from IEEE must be obtained for all other uses, in any current or future media, including reprinting/republishing this material for advertising or promotional purposes, creating new collective works, for resale or redistribution to servers or lists, or reuse of any copyrighted component of this work in other works." 


\section{Studio-based learning in a first year engineering curriculum: Exploring students' learning experiences and reflections using the rich picture method}

\author{
Franziska Trede \\ Institute for Media and Learning \\ University of Technology Sydney \\ Sydney, Australia \\ franziska.trede@uts.edu.au
}

\author{
Robin Braun \\ School of Electrical and Data Engineering \\ University of Technology Sydney \\ Sydney, Australia \\ robin.braun@uts.edu.au
}

\author{
Wayne Brookes \\ School of Electrical and Data Engineering \\ University of Technology Sydney \\ Sydney, Australia \\ wayne.brookes@uts.edu.au
}

\begin{abstract}
We have described engineering students in their first year participating in a "studio" based experience. We used a rich picture method imbedded in research interviews to explore student's attitudes to, and understandings of their studio experience. Our findings demonstrate that this research method produces an enriched understanding of and deep insights into student experiences in the studio.
\end{abstract}

Keywords-Studio-based learning, First year engineering experience, rich picture method

\section{INTRODUCTION}

The advent of pervasive information technology in higher education has enabled the introduction of new paradigms. It has enabled us to think very differently about the way that we educate future engineers. In particular, it has enabled us to move from Mode 1 teaching (lectures and tutorials) to Mode 2 teaching (students' active participation in generating new knowledge in a maker space) [17]. "In Mode 1 problems are set and solved in the context governed by the largely academic interests of a specific community. In Mode 2 knowledge is carried out in the context of application[17]. The Studio as implemented in our engineering program is just such an experience[16].

Introducing studio-based learning in first-year engineering curricula is no longer innovative[10] but what is new is to explore students' experiences and reflections of it using the rich picture method. The purpose of this study was to explore how students experience and make sense of a first-year studio using the rich picture method to enable participants to express their emotional and cognitive reasoning through visual communication.

The first year of university study sets the scene for learning and engagement in a higher education environment and it is the most crucial year for retention[2]. Successful transition from secondary to tertiary education has been identified to include intellectual engagement and motivation to study[8]. It is not surprising then that universities pay specific attention to student engagement in the first-year curriculum[12]. There is a drive towards more active and collaborative learning approaches and a trend away from didactic teaching methods such as traditional lectures. More importance is placed on students' active participation and learning and teaching strategies that embrace not only learning of theoretical and intellectual contents but also learning for personal development and professional responsibility[9].

In addition to a successful transition into tertiary education there is an increasing expectation that universities prepare graduates for a successful transition out of university and into employment. Knowledge and technical skills are no longer enough to be competitive in the job market. Students are expected to also provide evidence of practice capabilities and dispositions that include critical thinking, complex problem solving, and working effectively in teams[6][13]. With this change of focus in university education to applying knowledge in practice contexts and demonstrating practice capability, a change of focus of pedagogies is required that provide self-directed, practice-based learning opportunities that equip students with lifelong learning skills and personal development[3]. Barnett contended that "knowing and acting will be brought into a complex but productive relationship" in higher education programs that offer real-world, actionoriented learning experiences[3]. Studio-based learning can offer these learning experiences because it uses a teamwork approach, applies inquiry-based learning to real-world problems and is underpinned by active, collaborative and open-ended learning principles.

There are two proposed reasons for why studio-based learning in the first year is of value. Firstly, a first-year studio responds to the imperative to provide engaging learning environments that can foster personal development and enhance a sense of belonging. Secondly, it prepares students for collaborative, critical thinking and engaging with illdefined problems[7] which are crucial professional capabilities required in the future world of work. In this study a first-year studio was tested for its value as a beneficial transition pedagogy that enhances student engagement.

\section{A. Project Context And Research Questions}

The faculty of engineering and information technology of an Australian technology university has introduced studiobased learning faculty-wide and infused in each year of the curriculum as one of its innovative, practice-oriented approaches to better prepare students for the future world of work and more specifically to develop their learning and practice capabilities. Studios are introduced as early as in semester 2 in year 1 of the bachelor programs with the aim to provide students with close-to-authentic learning experiences and foster professional practice capabilities. A first-year subject was transformed into studio-based learning and was taught for the second time in 2018 when this study took place.

In the Data Engineering program a subject entitled Fundamentals Studio A has been introduced in year 1. The purpose of Studio A is to provide an environment in which students can translate and articulate the knowledge and wisdom they have or can gain into what they can do. This study was conducted in Spring 2018 when this Studio was taught for the second time. 
The aim was to better understand the potential of a firstyear studio as a transition pedagogy from students' perspectives. The research question that guided this paper was what can be learnt from students' perspectives to better understand the opportunities and challenges of a first-year studio?

Sub questions were:

- What insights emerged about self and studio-based learning through participants' drawings?

- What are first-year students' perceptions of teamwork?

\section{B. Methods}

\section{1) Participants}

Participants were recruited from this first-year subject Studio A Fundamentals in the Bachelor of Data Engineering in an Australian technology university. The researcher invited the 36 strong student cohort to participate. 10 students (28\%) participated in this study which had university ethics approval. Six were male and 4 were female. This comprised $20 \%$ of male and $57 \%$ of female student participation. All had completed secondary schooling in Australia and two came from families with non-English speaking backgrounds. Eight participants were first year students with one having had a gap year and the remaining two participants were in their second year of studies.

\section{2) Rich picture method}

Engineering is a professional discipline that identifies as a science based on scientific knowledge that is context-free, value neutral, representational and universal[11]. In contrast the rich picture method which is an arts-based approach resides within the qualitative paradigm and communicates deep human experiences and understanding and they can depict hidden meaning[4]. There are three distinctive features to arts-based approaches in research[14]: it is a non-discursive and intuitive approach to knowing. Drawings do not solve problems but express them. Secondly, arts-based approaches enable seeing the world from a different perspective using drawings as a visual communication tool. Thirdly, the aim of arts-based approaches is to provoke and evoke a response from the viewer beyond the research context. Because engagement and collaborative learning are social, interactive learning strategies that involve self and emotions the rich picture method seemed a suitable approach to connect participants' unconscious knowing and emotions to learning[5].

\section{3) Data collection strategy:}

The data collection strategy consisted of two phases, a baseline interview in week $2 / 3$ and a post-studio interview in week 13/14. Interviews were semi-structured, lasted 40 minutes on average and were recorded and transcribed. Each interview included drawing a picture of studio-based learning adapting a strategy from the rich picture method[4]. The baseline interview commenced with introductory demographic questions. It engaged participants in a conversation about their experiences of self-directed, collaborative learning and teamwork in secondary education and at university so far, and when was the last time that they had drawn pictures. Participants were then asked to draw. The instruction was: use these four colour pencils and draw on this DIN A3 paper what studio-based learning is all about for you. Include yourself somewhere in the picture. Don't worry, it is an advantage not to be artistic. You can be as abstract or concrete as you like. You have 3 minutes. Then participants were asked to explain and discuss what their drawing symbolizes for them. The follow-up interview occurred during the final two weeks of semester. Participants were asked about the highlights and lowlights of their studio experience, and what they had learnt. Then the rich picture method was used underpinned by the question, what was studio-based learning all about with the same instructions as in the baseline interview.

\section{4) Data analysis}

Data analysis consisted of three phases pre-understanding (description), deeper understanding (shared interpretation) and critical understanding (critiquing interpretations) following the hermeneutic tradition of a question and answer dialogue[15]. Phase 1 was conducted as a question and answer dialogue between the researcher and each participant. Phase 2 was a dialogue between the researcher and participants based on the visual products whereas phase 3 was conducted between the researcher and the collected transcripts and drawings. The visual data was interpreted together with the accompanying text and not out of this con-text. Preliminary findings were presented to academics whose helpful, insightful questions and comments further informed text and drawing interpretations. Due to its qualitative nature this project provides in-depth snapshots of individual students' perspectives. There was no intention to make representational claims. To observe anonymity and confidentiality of the participants pseudonyms were used.

\section{Discussion OF FINDINGS}

\section{A. Experiences and reflections of teamwork from the baseline interview}

Most of the participants had not experienced teamwork in secondary education or at least not since year 9 . Some reported studying in buddy groups but they were more supportive of each other rather than collaborative in nature. Participants described studying towards the higher education certificate as a generally individual, competitive and stressful experience. In contrast to the secondary education experience, all participants reported that they had been exposed to teamwork and collaborative learning in subjects in semester 1 in year 1 at university. These teamwork experiences varied ranging from being enjoyable and learning to work with peers to "people slacking off" and "some people don't show up but still manage to pass". "Teamwork is so much better when you share the same interests and goals". Despite these mixed experiences with teamwork and studios being unfamiliar to students, there was a sense of excitement in the baseline interview about this studio which is evidenced by the following quotes:

- "I enjoy working with people I haven't met before; possibility of networking for the future. I like to see them get passionate “

- "I like how dedicated the group is. I have not been in a group that wants to do something".

- "Everybody threw in ideas what the product should look like. Everybody has respect for everyone. Even the quiet people are more talkative".

- "This is the first subject where there is no right or wrong answer". 
- "This is the first subject where there is no yes or no. It has all colours of the rainbow. It makes it uncomfortable".

- "Lack of structure is good but very strange. It needs getting used to".

- "Good balance between guidance from facilitators and freedom to choose and learn with peers".

- "I guess I enjoy the studio. There will probably be a time, maybe at 6 weeks, where I say I really hate this, but not yet, which is good".

- "The more group work you do the more experience you get and pick up how to behave; how to deal with certain situations".

Participants described studio-based learning as "Selfdriven learning and experiencing not knowing". They appeared sensitised to this highly interactive approach to learning. Some provided a rationale for studios, for example: "Technology is always changing - we need to learn and figure out things. We need to do that learning - learning how to learn".

\section{B. Insights from rich picture method}

All participants confessed that they had not drawn anything since kindergarten. Although the rich picture method appeared a daunting exercise to some, none had difficulty to draw their visualisation of studio-based learning. Andrew who was the only one who did not use up the entire paper space justified himself by saying "If I drew big, you expect bigger things. [and he added] I haven't drawn in ages". He drew three overlapping circles explaining that "studios are made up of three core learning methods: teamwork, individual learning and content". He drew himself into the centre of the overlapping circle because he was the studio leader and learners had to connect with all three circles. The most abstract drawing consisted of three separate circles; each increasing in size and adding more colour. Frank explained "the small red circle is myself as a circular entity. The sizes of the circles represent growth of knowledge. The coloured circles are representing the group dynamics: different knowledge, different people, [and together] creating something more complex". Overall, the drawings symbolised studio-based learning as dynamic and open with many arrows going in reciprocal directions. Only Thilo drew a one-directional perception of studio-based learning which revealed his discomfort of a non-structured learning environment and his hope for order: "Something needs to be done urgently. At the moment we are everywhere. The connections are not clear. I want to get that fixed". There was a distinct tolerance for collective, explorative learning in an unstructured environment.

The drawings from the follow-up interviews symbolised the ups-and downs of teamwork in studio-based learning. Thilo drew a journey through fog and rainstorms, Christine drew a roller-coaster because "it is a good analogy" of her experience of studio-based learning. Tapan drew orange clouds above team members' head symbolising "all the ideas and the new things we've learned that we bring each week. ... The solution is drawn like a box. It got a padlock on it.
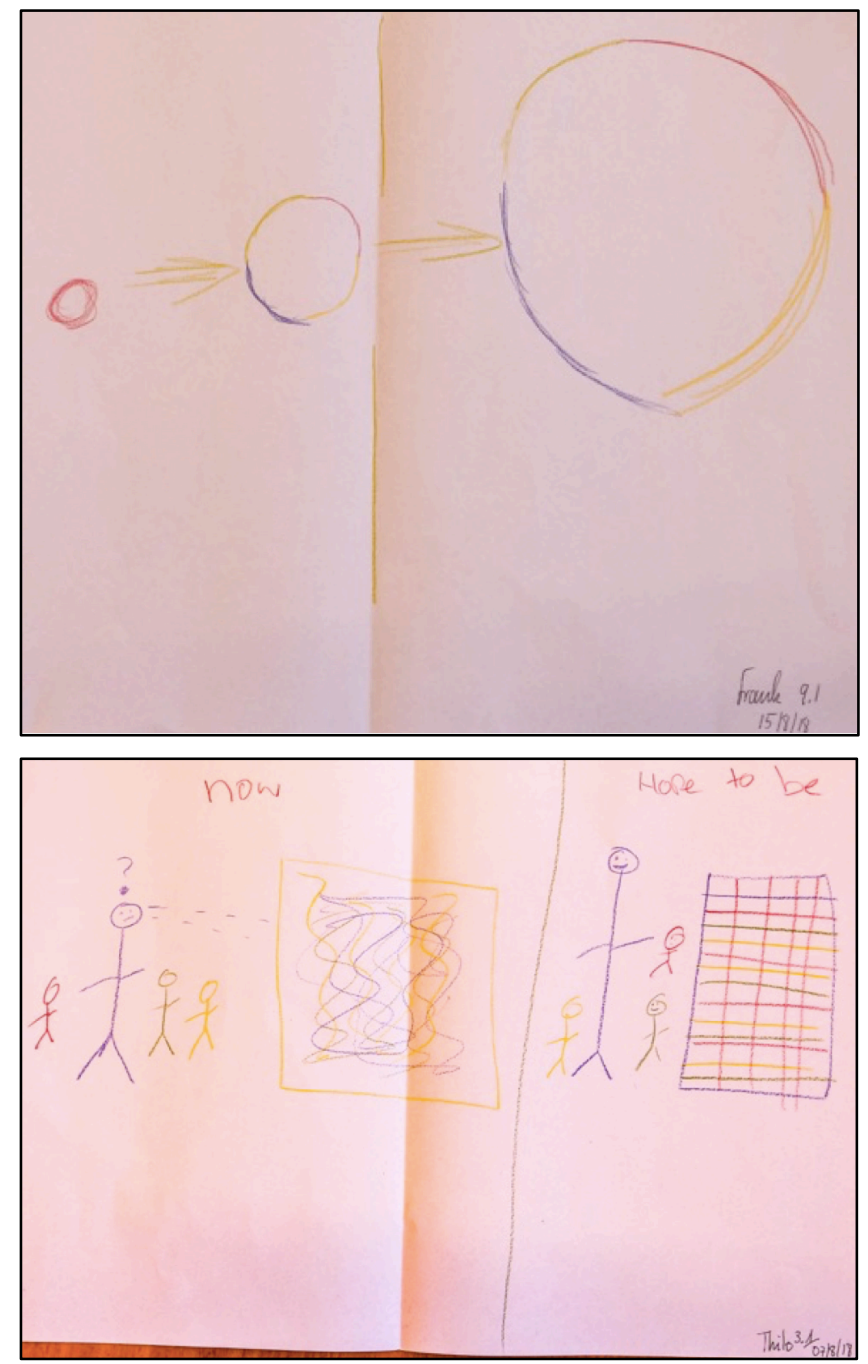

We need a key but we still don't have one". There was a theme of engaging with uncertainty, exploring possibilities and not knowing the solution. Some participants found this energising and empowering whereas others felt anxious or frustrated. Another theme that emerged from the follow-up drawings was taking responsibility for learning and contributing timely to the team product. Ruth drew herself and one other student pushing a big rock uphill and two other team members sitting on the rock: "Studio-based learning is like a hill with some barriers on the way. ...I think it's just been a bit more stressful on me and this other person in my group". Ruth was disappointed in the limited sense of professional responsibility and active participation of others in her team. She had no answer to why others did not contribute more actively. As the team leader Anthony drew many arrows going from him to team members and the product: "the arrows are work load, task delegation and getting feedback. I am the team leader trying to delegate tasks and working out how I can get others interested to do the work". Anthony was also disappointed with team members' active collaboration. "One person held us back. He was too busy. The consequence was someone else did the work". Anthony thought it would be easier to work individually yet he understood that collaboration was essential in the real world. The drawings enabled access to deeper meaning of collaborative learning and how they positioned themselves in this collaboration. The drawings also vividly expressed the emotional struggles that participants experienced in this studio. 

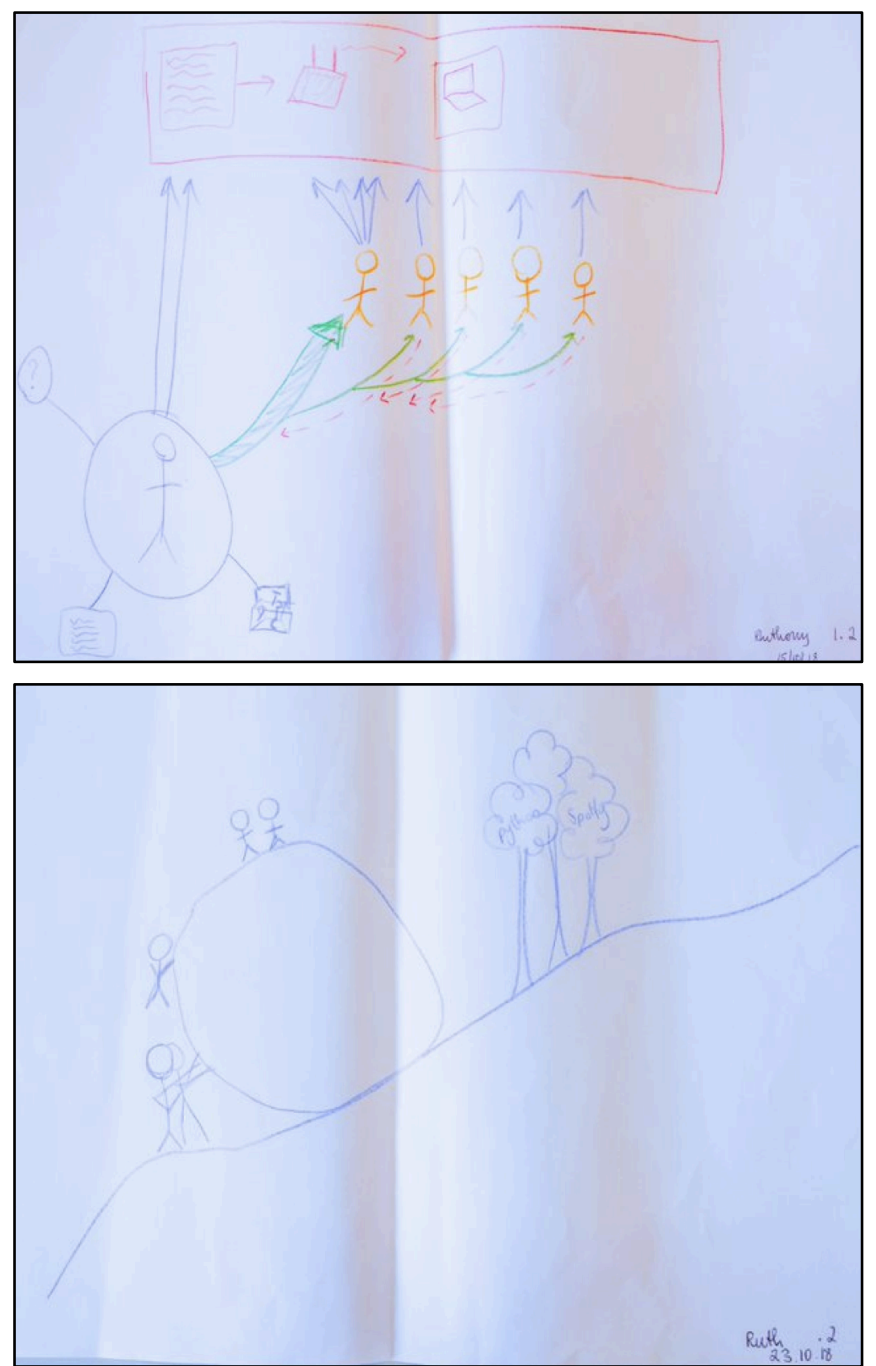

C. Perceptions of personal development and teamwork in follow-up interviews

Participants learnt a great deal about themselves. Personal development related to confidence, learning preferences and self-responsibility which is evidenced through the following sample quotes:

- "I do kind of prefer the traditional structure, because that's the easy way out. ... I think, going into it, where they said, oh, it's okay to fail, I'll admit, I thought that seems a bit un-teacher-like. Isn't the point of you being here to teach us? Coming out of it, I realise, that it's probably the correct approach" (David)

- 'I think I've learnt that I can do things that I'm not used to or what I'm new to... I was really scared at that thought since you have to teach everything yourself. Which I'm not good at teaching myself anything so I need someone to actually guide me but we are near to complete the product" (Christine).

- "There was one week I said I would do something and then I ended up not doing it by the next week. I was sternly talked to by the rest of the group that I wasn't pulling my weight that week. I thought yeah, that's fair enough. So, this changed how I'd been functioning since then. Yeah" (Tapan).

- "There was no criteria and no time factor. I thoroughly enjoyed that."
These insights about self and particularly how they engaged with learning can have valuable impact for their future approach to studying and ultimately to working. Participants gained self-confidence, changed their attitudes towards self-directed learning and increased their individual learner agency.

In addition, the follow-up interviews revealed that participants had gained much deeper insights about the complexity of teamwork and what it takes to collaborate as evidenced in the following quotes:

- "I learnt that it is difficult to work in a team"

- "I got frustrated when people said, I don't know about this, you do it. That's people, you are coming across in life. There is nothing you can do to control that."

- "Studios sound good in principle. If all people were interested and keen with goals in mind it would work. But people are here to just pass."

- "People did not show initiative"

The social dimension of teamwork was amplified as evidenced in these quotes. They relate closely to individual agency and related concepts of motivation, responsibility and interest and give voice to a sense of helplessness in cultivating team agency. Participants amplified how they felt about teamwork and collaboration evocatively through their drawings. Participants learnt to understand that teamwork relies not only on individual agency but also on working together with others to co-create new knowledge, insights and produce a product[1]. The teams seemed to have missed opportunities to create more interactive learning environments.

\section{CONCLUSION}

Findings from this project provide a rich, in-depth snapshot of students' experiences and reflections of studiobased learning in the first year. From these findings the following conclusions can be drawn. Despite their ups and downs, participants of this study are advocates of studio-based learning and want to see first year studios to continue. Benefits of studio-based learning included a focus on exploring ideas, freedom to learn, gaining deeper insights into self and others, and development of professional dispositions such as being responsible, showing initiative and being creative. However, this study also highlighted the struggles participants experienced in this first-year studios with a particular focus of its collaborative elements. The rich picture method is an appropriate method to better understand the opportunities and challenges of a first-year studio. They enabled participants to get in touch with their feelings and expressive capabilities to enhance and enrich their reflective learning. The findings from this study strongly suggest that first-year studios need to carefully induct and support students to navigate collaborative learning.

\section{ACKNOWLEDGMENT}

We would like to acknowledge funding for interview transcriptions and technical preparation of the drawings from the Institute for Interactive Media and Learning at the University of Technology Sydney.

\section{REFERENCES}

[1] Arvaja, M., Salovaara, H., Häkkinen, P., Järvelä, S. (2007). Combining individual and group-level perspectives for studying collaborative 
knowledge construction in context, Learning and Instruction, 17(4), 448-459.

[2] Australian Council for Education Research (2008). Initial educational experiences of tertiary students, LSAY Briefing, 14, 1-8.

[3] Barnett R (2012) Framing Education for practice. In Higgs J, Fish D, Goulter I, Loftus S, Reid J-A and Trede F (eds.) Education for future practice. Rotterdam: Sense Publishers, pp. 15-28.

[4] Bell, S., Berg, T. and Morse S. (2016). Rich pictures method: Encouraging resilient communities, London: Routledge.

[5] Eisner, E. (2008). Art and knowledge. In Gary Knowles \& Ardra L. Cole (Eds)., Handbook of the arts in qualitative research, (pp. 3-12). Thousand Oaks, CA: Sage.

[6] Foundation for Young Australians.(2016). The new work mindset: 7 new job clusters to help young people to navigate the new work order. Melbourne, VIC: FYA.

[7] Jonassen, D. (2011). "Supporting Problem Solving in PBL", Interdisciplinary Journal of Problem-Based Learning, 5 (2), 95-112.

[8] Kift, S (2009). Articulating a transition pedagogy to scaffold and to enhance the first year student experience in Australian higher education: final report for senior ALTC fellowship program. Sydney: Australian Learning and Teaching Council.

[9] Kreber, C. (2016). Educating for civic-mindedness: Nurturing authentic professional identities through transformative higher education. New York, NY: Routledge.

[10] Little, P. and Cardenas, M. (2001). Use of "studio" methods in the introductory engineering design curriculum, Journal of Engineering Education, 90(3), 309-318.

[11] Maguire R, Egan A, Hyland P and Maguire P (2017) Engaging students emotionally: the role of emotional intelligence in predicting cognitive and affective engagement in higher education. Higher Education Research and Development 36(2): 343-357.

[12] Nelson, K. and Clarke, J. (2014). The first year experience: looking back to inform the future, HERDSA Review of Higher Education, 1, 23-46.

[13] OECD (2013) “Assessment of Higher education Learning Outcomes". AHELO. Feasibility study Report. Vol 2. Data Analysis and National Experiences.

[14] Schreier, M (2017). Contexts of qualitative research: arts-based research, mixed methods, and emergent methods . Forum Qualitative Sozialforschung / Forum: Qualiative Social Research, 18(2), Art. 6

[15] Trede, F., \& Loftus, S. (2010). Hermeneutic research: Exploring human understanding. J. In Higgs, N. Cherry, R. Macklin, \& R. Ajjawi (Eds.), Researching practice: A discourse on qualitative methodologies (pp. 185-196). Rotterdam: Sense Publishers.

[16] Braun, R., Miller, G., Chaczko, Z. and Brookes, W., 2018, April. First experiences of Studios in the new Data Engineering program. In 2018 17th International Conference on Information Technology Based Higher Education and Training (ITHET) (pp. 1-5). IEEE.

[17] Gibbons, M., Limoges, C., Schwartzman, S., Nowotny, H., Trow, M. and Scott, P., 1994. The new production of knowledge: the dynamics of science and research in contemporary societies, London: SAGE Publication. 